\title{
Assessment of Nephrotoxicity of Repeated Use of Monosodium Glutamate in Adult Albino Rats
}

\section{Hosam Eldin Hussein Osman', Said Said Elshama², Ayman El-Meghawry El- Kenawy3}

\author{
${ }_{1}^{1}$ Anatomy Department, Faculty of Medicine, Taif University (KSA) and Al-Azhar University (Egypt) \\ ${ }^{2}$ Forensic Medicine and Clinical Toxicology Department, Faculty of Medicine, Taif University and Suez Canal University \\ (Egypt) \\ ${ }^{3}$ Pathology Department, Faculty of Medicine, Taif University and Menoufiya University (Egypt)
}

Corresponding author

Said S. Elshama: saidelshama@yahoo.com

All rights reserved.

\begin{abstract}
Introduction: Monosodium glutamate (MSG) is one of the most common food additives. It is not a nutrient, vitamin, or mineral and has not any health benefits. The Food and Drug Administration (FDA) indicates that monosodium glutamate is a safe food additive, but some studies indicated that it has a toxic effect. So, its use remains controversial in spite of its increasing consumption in fast and canned foods. The kidney has a vital role for elimination of MSG because it performs the excretion of many toxic metabolic waste products. Aim of the study: Study of biochemical, histological, ultrastructural and histochemical changes of kidney caused by repeated intake of MSG. Materials and Methods: Sixty albino rats divided into three equal groups, first group (control) received $2 \mathrm{ml}$ of distilled water daily for 12 weeks, Second and third group received 7.5 and $15 \mathrm{mg} / \mathrm{kg} /$ day of MSG orally for 12 weeks respectively. Biochemical changes were investigated by the renal function tests. Assessment of histopathological changes of kidney was done by using light microscope, electron microscope, and histochemical studies. Results: After repeated use of MSG, light microscope and electron microscope examination revealed histopathological changes such as hypertrophy and degeneration of renal tubules epithelium, enlarged glomeruli with narrowing glomerular capsular space and flat epithelium of Bowman's capsule, focal loss of the brush border of epithelial lining of proximal renal tubules, disturbance of the nuclear membrane, degenerated rough endoplasmic reticulum, increased number of lysosomes and cell death. Histochemical studies showed degenerative and necrotic areas of renal tissues especially renal tubules and glomeruli. These changes induced statistical significant increase of serum urea and creatinine. Conclusions: repeated use of MSG caused nephrotoxicity of rats manifested as renal histopathological, ultrastructural, histochemical, and biochemical changes in a dosedependent manner.
\end{abstract}

Keywords Monosodium glutamate, histopathology, biomarkers, kidney

\section{Introduction}

$\mathrm{M}$ onosodium glutamate (MSG) is one of the most common food additives. It has a flavor function because it increases perception of sweetness and diminishes the sourness of food. It is used in many commercial packed foods such as magi soup, noodles, and household cooking (Samuels, 1999).
Trade names of monosodium glutamate include Ajinomoto, Vetsin, Ac'cent and Tasting Powder. It was once made predominantly from wheat gluten, but it is now made mostly from the fermentation of carbohydrates with a nitrogen source, using bacterial or yeast species from genera such as Brevibacterium, Arthrobacter, 
Microbacterium, Micrococcus and Corynebacterium (Willams and Woessner, 2009).

MSG is not a nutrient, vitamin, or mineral and has not any health benefits but it is a slow poison. The part of MSG that negatively affects the human body is the "glutamate", not the sodium. The breakdown of MSG typically consists of $78 \%$ glutamate, $12 \%$ sodium, and about $10 \%$ water (Stevenson, 2000).

The Food and Drug Administration (FDA) of the United States indicates that monosodium glutamate is a safe food additive without an upper limit intake requirement. Some studies indicate that MSG is toxic to human and experimental animals in spite of its stimulatory effect on taste and appetite. So, the use of MSG remains controversial and the FDA requires that MSG should be listed on the label when it is added to food (Mozes and Sefcikova, 2004).

In general, the natural glutamic acid found in food does not cause problems, but the synthetic free glutamic acid formed during industrial processing is a toxin. In addition, when MSG is formed using hydrochloric acid, the final product includes carcinogens (Geha et al., 1998).

MSG is excitotoxin food additives. It is also known that excitotoxins themselves can cause the generation of numerous amounts of free radicals. These radicals induce lipid peroxidation (oxidation of membrane fats) resulting in the production of a metabolite called 4-hydroxynonenal. This chemical inhibits the glutamate transporter, thus allowing glutamate to accumulate in the brain destroying the neurons. Recently, it has been shown that this occurs not only within the brain, but also within other tissues and organs (Freeman, 2006).

Effects of excitotoxin food additives generally are not dramatic. Some individuals may be especially sensitive and develop severe symptoms, but in most instances the effects are subtle and develop over a long period of time (Rogers and Blundell, 1990).

According to WHO, There is no restriction for dose of MSG but the recommended dose is $1 \mathrm{~g}$ per serving, however some adverse effects were produced even with this recommended dose. On the other hand, some studies confirmed that chronic administration of MSG induce oxidative stress and toxicity in experimental animals. With the increasing consumption of MSG for a long period in fast and canned foods, daily intake may be exceeding the recommended dose and toxic effects are the final result for this chronic abuse of MSG (Vinodini et al., 2010).

The kidney has a vital role for elimination of monosodium glutamate (Egbuonu et al., 2009).
So the aim of this study is to assess nephrotoxic effects of repeated use of MSG in adult albino rats (biochemically, histologically and histochemically)

\section{Materials and methods}

Sixty adult albino healthy rats of both sexes weighing $(200-250 \mathrm{~g})$ were subjected for the study. They were housed in air- conditioned, humidity-controlled cages. Rats had free access to water and food during the experimental period.

The rats were divided into three equal groups (each $\mathrm{n}=20$ ). The first was the control group, each rat received $2 \mathrm{ml}$ of distilled water/day orally for 12 weeks. The second group received monosodium glutamate 7.5 $\mathrm{mg} / \mathrm{kg} /$ day dissolved in distilled water for 12 weeks. The third group received monosodium glutamate 15 $\mathrm{mg} / \mathrm{kg} /$ day dissolved in distilled water for 12 weeks. Oral administration of (MSG) achieved by gastric gavage.

Animals were sacrificed 24 hours after the last dose of MSG. Blood samples were collected after puncture of hearts of rats and centrifuged 3000 round per minute for 10 minutes to obtain the serum to assay the renal function tests (serum urea and creatinine).

\section{Assay of renal function tests}

\section{Serum creatinine}

It was determined by Jaffe reaction (Wilding and Kennedy, 1977).

\section{Serum urea}

It was determined by Berthelot method (Alexander and Griffith, 1992).

\section{Histological and histochemical studies}

Following the serum collection, abdominal incision was done and kidney was removed. Renal tissue specimens were collected from both control group and test groups and then fixed in $10 \%$ neutral buffered formalin. The fixed specimens were then trimmed, washed and dehydrated in ascending grades of alcohol, cleared in xylene, embedded in paraffin, sectioned at 4-6 $\mu \mathrm{m}$ thickness and stained by haematoxylen and eosin and Periodic acid Schiff (PAS) according to Drury and Wallington (1980).

Ultrastructural studies were done by Transmission Electron Microscope (TEM). Renal tissue specimens were cut into five pieces to analyze different renal areas. Fixation was done in $(2 \%$ glutaraldyde and $0.6 \%$ paraformaldehyde). Post-fixation was continued with $2 \%$ osmium tetroxyde for $2 \mathrm{hrs}$. The specimens were then washed with phosphate buffer, dehydrated with graded acetone and then embedded in araldite CY212 to make tissue blocks. Semithin $(1 \mu \mathrm{m})$ as well as ultrathin sections $(70-80 \mathrm{~nm})$ were cut by ultra 
microtome and toludine blue stain. The sections were stained with uranylacetate and lead acetate. Examination under a Transmission Electron Microscope was performed and evaluated by Philips 400T electron microscope (Bancroft and Gamble, 2002).

\section{Statistical analysis}

Results of this study were analyzed by using non parametric test. Assessment of statistical significant differences between compared groups was done by independent sample T-test. Significant $p$ value is less than 0.05 .

\section{Ethical considerations}

The most appropriate animal species was chosen for this research. Promotion of a high standard of care and animal well-being at all times was done. Appropriate sample size was calculated by using the fewest number of animals to obtain statistically valid results. Painful procedures were performed with ether inhalation to avoid distress and pain. Our standards of animal care and administration met those required by applicable international laws and regulations.

\section{Results}

\section{Biochemical parameters}

Table (1) shows significant increase of serum urea and creatinine in groups 2 and 3 when compared with the control group.

\section{Histopathological findings by light microscope Control group}

Figure (1) shows the standard structure of the kidney of the control group. The glomerular capsule is lined with a flat epithelium. The proximal and distal convoluted tubules are lined with cubic epithelium. The thick descending and ascending parts of Henle's loops are lined with simple cubical epithelium. The collecting tubules are lined with low simple cubic epithelium.

\section{Second group}

Figure (2) shows mild increase of renal glomeruli vascularity and space of the glomerular capsule. There is a mild edema of epithelium of proximal and distal convoluted tubules.

\section{Third group}

Figure (3) shows renal damage which represented as hypertrophy and degeneration of renal tubules epithelium. There is a desquamated single epithelial cell of some renal tubules to the lumen. Vascular glomeruli are enlarged with narrowing glomerular capsular space and flat epithelium lining of Bowman s capsule. There are many areas of tubular damage.

\section{Histochemical findings by light microscope Control group}

Figure (4) shows kidney of control group. Severe positive PAS reaction of glomeruli appears with positive PAS of cytoplasm and brush border of proximal convoluted tubules.

\section{Second group}

Figure (5) shows a mild increase of intensity of PAS reaction in the renal tissue but it is different from positive reaction of PAS of kidney of control group.

\section{Third group}

Figure (6) shows marked decrease of PAS reaction of degenerative and necrotic areas of renal tissues especially renal tubules and glomeruli.

\section{Histopathological findings by electron microscope}

\section{Control group}

Figure (7) shows the ultrastructure of the kidney of the control group. A brush border of epithelium of proximal renal tubule, basal or central nucleus, apical endocytic vesicles, occasional lysosomes, and elongate or round mitochondria. Cisternal profiles of rough endoplasmic reticulum is between the mitochondria. Endothelial cells of the glomerular capillaries were fenestrated with large pores.

The podocytes were in contact with the basement membrane by extensions of their cytoplasm known as foot processes in the urinary space.

\section{Second group}

Figure (8) shows mild ultrastructural changes, mild enlargement of glomeruli, mild swelling of capillary endothelium, mild swelling of mitochondria, dark nonvacuolated protoplasm and mild degeneration of rough endoplasmic reticulum.

\section{Third group}

Figure (9) shows enlargement of the glomeruli with narrowing of the capillary lumen, swelling of the capillary endothelium and loss of the fenesrtae, focal loss of the brush border of epithelial lining of proximal renal tubules, chromatin condensation, swelling of several mitochondria with regression of their crestae. Disturbance of the nuclear membrane. Degenerated rough endoplasmic reticulum. Increased number of lysosomes and cell death. Displayed large number of cytoplasmic vacuoles. Disorganized brush border . 
Table (1): Mann-Whitney $U$ test for the analysis of the effect of repeated use of monosodium glutamate on renal function profile of rats.

\begin{tabular}{|c|c|c|c|}
\hline $\begin{array}{ll}\text { RFT } & \text { Group } \\
\end{array}$ & Group 1 & Group 2 & Group 3 \\
\hline S.Urea (mg/dl) & $14+2.2$ & $28.27+1.3^{*}$ & $42.15+4.3^{* *}$ \\
\hline S.Creatinine $(\mathrm{mg} / \mathrm{dl})$ & $0.41+0.07$ & $0.65+0.03 *$ & $0.85+0.09^{* *}$ \\
\hline
\end{tabular}

RFT $=$ Renal function tests

Group 1 = Control (received distilled water); Group 2 received $7.5 \mathrm{mg} / \mathrm{kg} /$ daily of MSG dissolved in distilled water; Group 3 received $15 \mathrm{mg} / \mathrm{kg} /$ daily of $M S G$ dissolved in distilled water.

${ }^{*}=p<0.05$ (significant difference in comparison with control group); ${ }^{*}=p<0.05$ (significant difference in comparison with second group).

Statistical analysis performed by non-parametric test (Mann Whitney $U$ test).

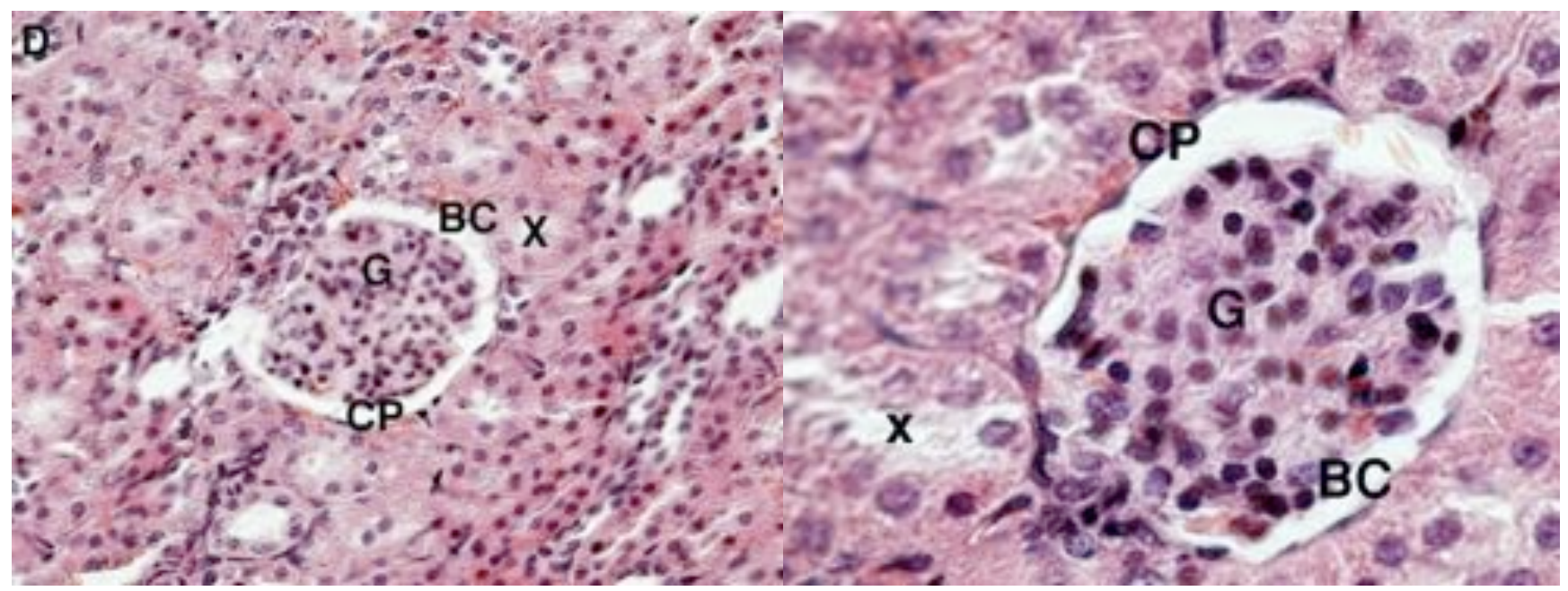

Figure (1): A photomicrograph shows the histological structure of the kidney of the control rats. The glomeruli (G) have flat epithelium lining the glomerular capsule (BC) with distinct capsular space (CP). The proximal tubules (X) are lined with typical cubic epithelium and distal convoluted tubules (D) are lined with the low simple cubic epithelium. H\&E (X400- X1000)

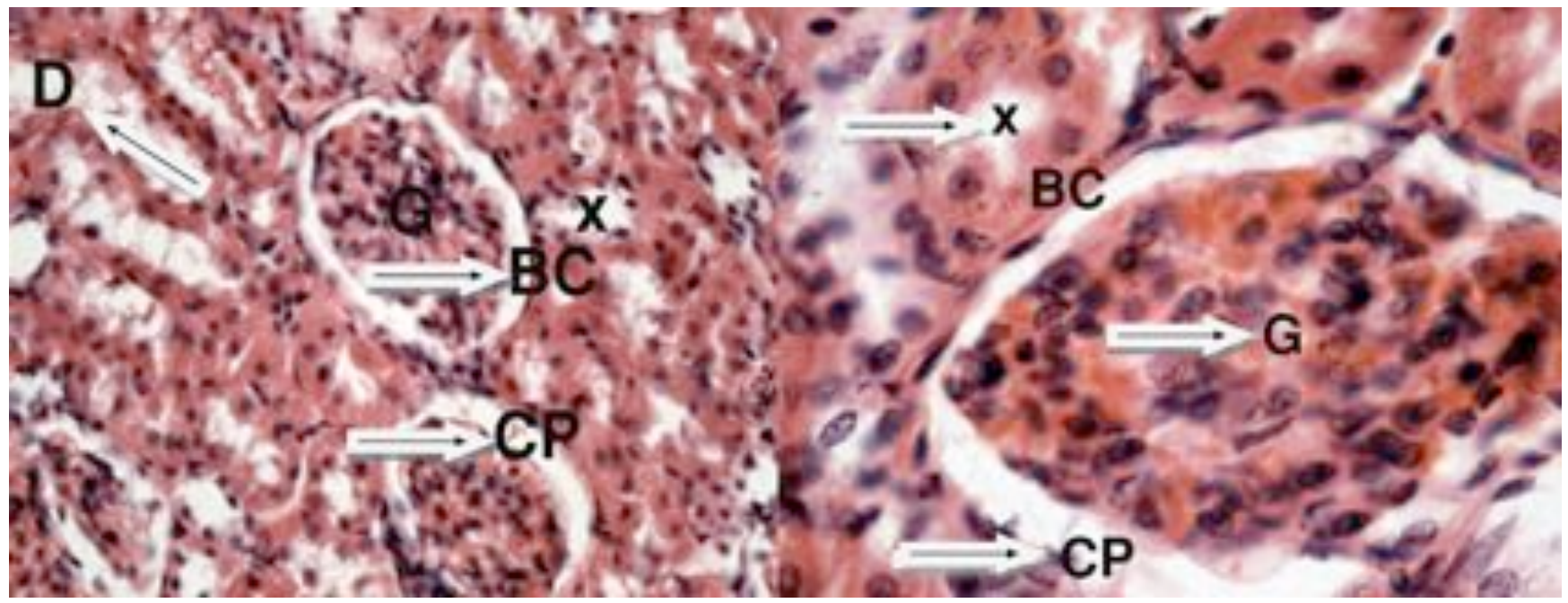

Figure (2): A photomicrograph shows the kidney of the second group. Mild increase of the vasculature of the renal glomeruli (G) and the glomerular capsular space (CP). Mild edema of epithelium of both proximal (X) and distal (D) convoluted tubules. Mild fibroses in the Bowman's capsule (BC). H\&E (X400- X1000) 


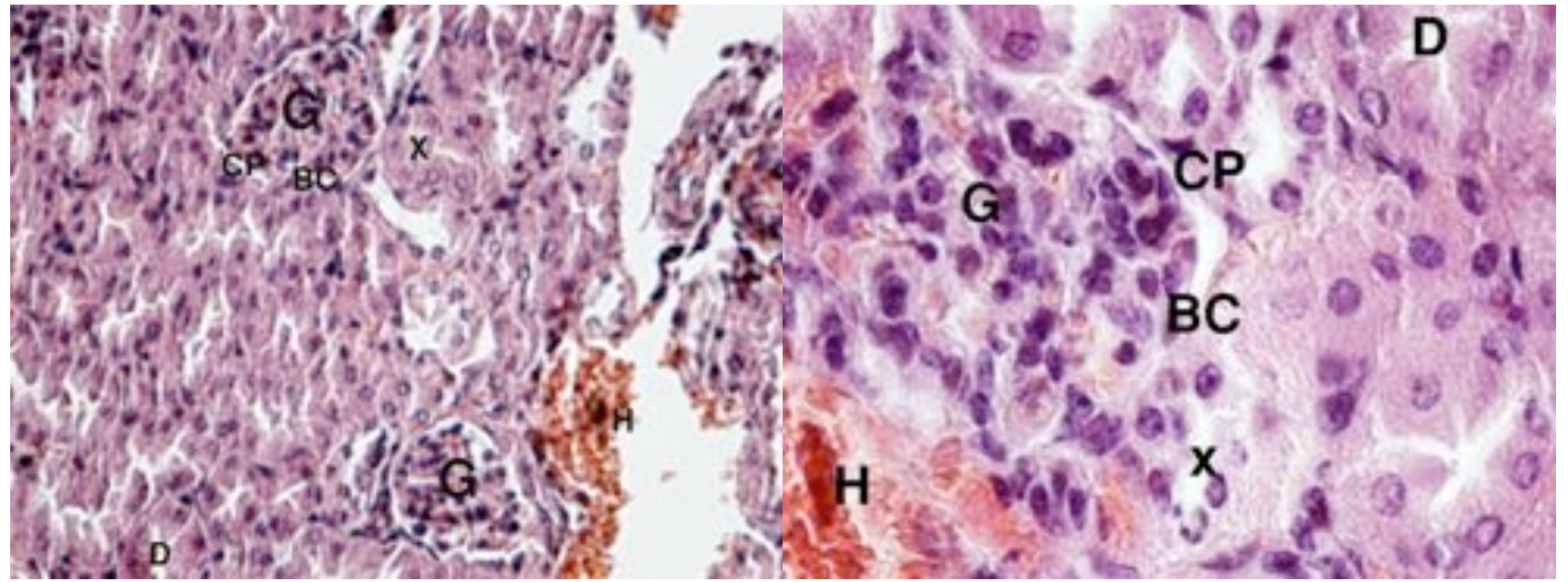

Figure (3): A photomicrograph shows the kidney of the third group. Enlarged vascular glomeruli (G), narrowing glomerular capsular space (CP) with flat epithelium lining of the Bowman's capsule (BC). Edema of some epithelial cells of the proximal(X) and distal (D) convoluted tubules. Capillaries are filled with blood cells, single desquamated cells of some tubules. H\&E (X400 - X1000)

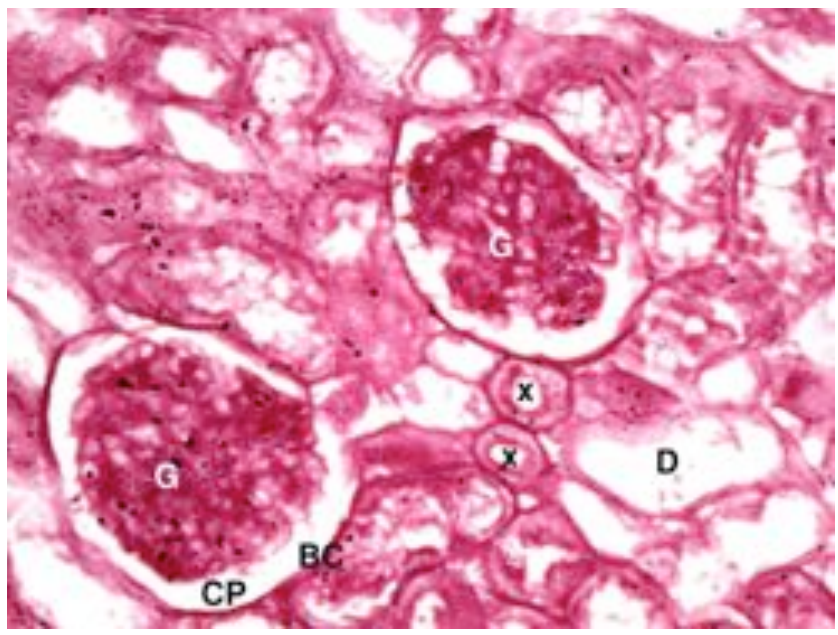

Figure (4): A photomicrograph shows the kidney of the control rats. Intense positive reaction of PAS of glomeruli (G), proximal (X) and distal (D) convoluted tubules, Bowman s capsule (BC) is lining with flat epithelium. There is distinct capsular space (CP). Periodic acid-Schiff's (X400)

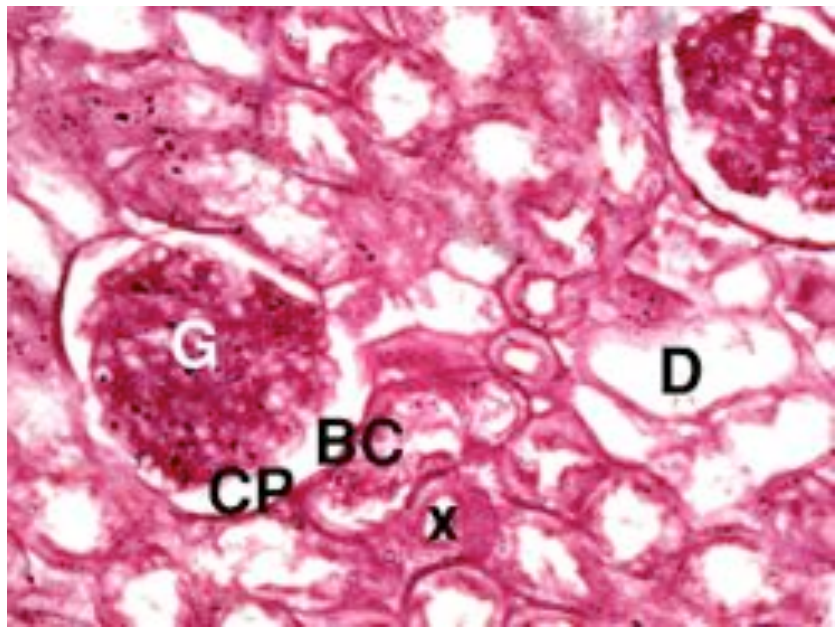

Figure (5): A photomicrograph shows kidney of second group. There is a mild increase of PAS positive reaction in renal glomeruli (G), Bowman's capsule (BC), proximal (X) and distal convoluted tubules (D). Periodic acid-Schiff's (X400) 


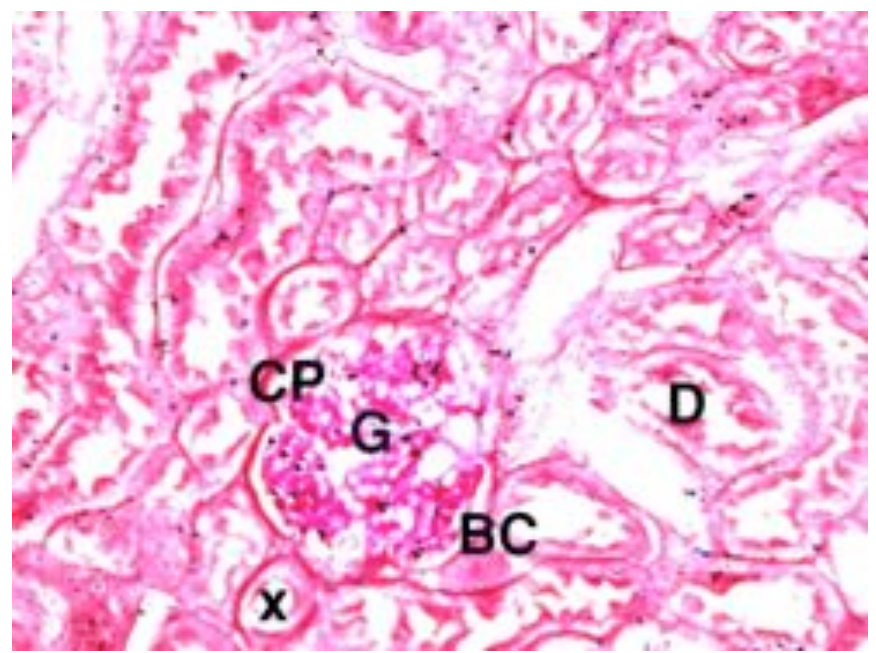

Figure (6): A photomicrograph shows kidney of the third group. There is a decrease of positive PAS reaction of renal glomeruli (G), Bowman's capsule (BC), proximal convoluted tubules (X) and distal convoluted tubules (D). Periodic acid-Schiff's (X400)

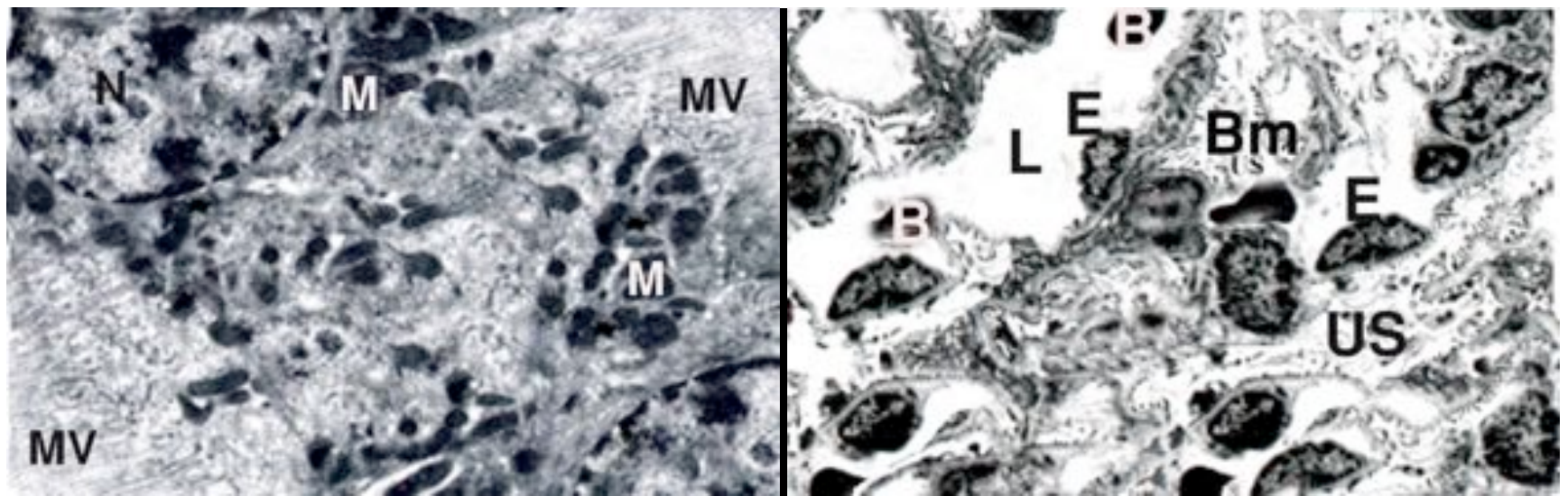

Figure (7): A photomicrograph shows kidney of the control rats. Euchromatic nuclei (N) of cells of the proximal convoluted tubule, mitochondria (M) having normal crestae, the brush border of the cells has microvilli (Mv). Glomerular structure shows the urinary space (US), basement membrane (BM) with capillary lumen (L) lined by endothelial cells (E) and blood cell (B). (X8000 - X4000)

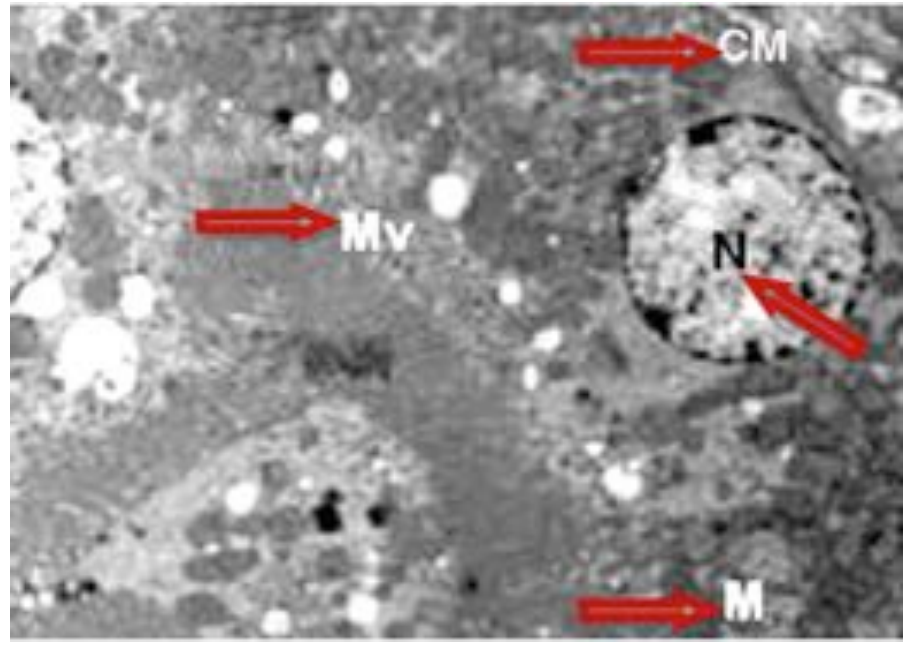

Figure (8): A photomicrograph shows ultrastructures of kidney of the second group. Euchromatic nuclei (N) and nucleolus (n), many mitochondria (M) and dark non-vacuolated protoplasm. Intact microvilli (Mv) and intact basement membrane (CM) with displayed distal convoluted tubules. (X4000) 


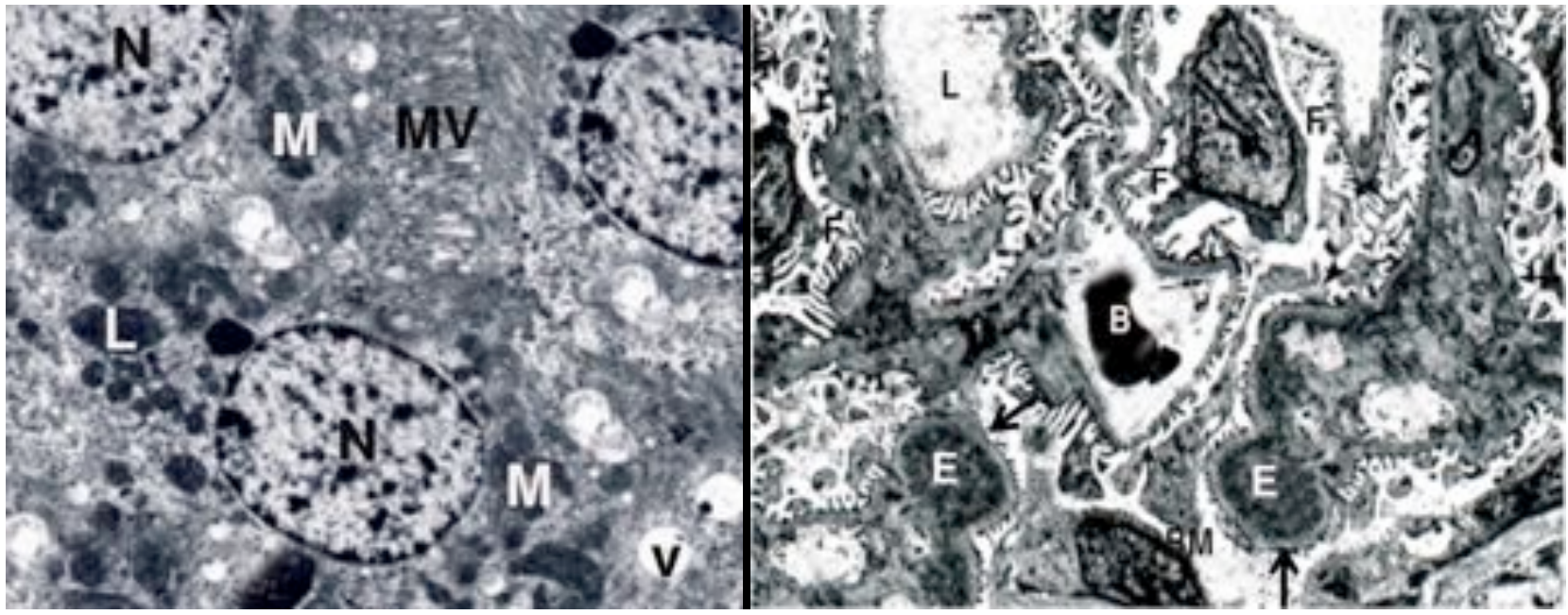

Figure (9): A photomicrograph shows ultrastructures of the kidney of the third group. Rounded heterochromatic nucleus (N) of proximal convoluted tubule, swollen mitochondria (M), disorganized apical microvilli (MV), numerous vacuoles $(\mathrm{V})$ and many lysosomes $(\mathrm{L})$. The arrow points to disorganized foot process with thickening of basement membrane (BM) filled with blood cell (B), swollen endothelial cells (E) widening capillary lumen (L). (X6000)

\section{Discussion}

MSG becomes the most popular taste enhancer in the last years. There are many controversial facts about its adverse effects, so doubts developed about safety of chronic use of MSG. Many researches to investigate its toxic effect on different organs especially which plays important role for its metabolism or its excretion such as the kidney. The present study shows its repeated use on the kidney by studying renal biochemical markers and histopathological changes.

According to Kaplan et al. (1988), assessment of serum urea and creatinine are indicators of renal function and any disturbance of its physiological balance will be depending on patholological condition of kidney.

The present study indicated that there is a statistical significant increase of serum urea and creatinine in third group which received $15 \mathrm{mg} / \mathrm{kg} /$ day of MSG in comparison to control group and second group which received $7.5 \mathrm{mg} / \mathrm{g} / \mathrm{kg} /$ day of $\mathrm{MSG}$. These results are consistent with Vindonini et al., (2010) who indicated that significant increase of renal biomarkers levels within 30 days after administration of high dose of MSG. Our results are contrast with results of Egbuonu et al., (2010) who indicated that significant decrease of serum urea and creatinine within 30 days in spite of high dose administration of MSG.

Our study confirmed that repeated use of MSG with high different doses leads to disturbance of physiological function of the kidney. This is contrast with Tawfik and Al-Badr (2012) who referred to the same result but with low doses and showed that increase of serum creatinine due to disturbance of functional capacity of tubular excretion resulting from oxidative stress induced by MSG on the kidney.

Zhang et al., (2004) explained that consumption of MSG in high concentration leads to affection of glomerular filtration and then increased serum renal biomarkers. Increased serum urea due to the change of the function of cytosolic, nuclear, and mitochondrial protein which involved in regulation of mitochondrial reactive oxygen species production. The increase of production of reactive oxygen species is nephrootoxic and then deterioration of the function capacity of the kidney will develop.

Our results were consistent with results of Tawfik and Al-Badr (2012) for toxic effect of MSG on renal biomarkers apart from its dose or duration of administration but it is in contrast with Egbuonu et al., (2009) who indicated that low dose of MSG may be nephroprotective.

The current study referred to severe histopathological changes of renal tissue after repeated administration of high dose of MSG. These pathological changes represent as tubular necrosis, interstitial fibrosis, and hypertrophy of epithelial cells of glomeruli. These results are consistent with Andrew (2007) who indicated that toxic effect of MSG depends on dose and duration of exposure.

Our results showed that histopathological changes of the kidney ranged from mild degenerative changes and necrosis of renal tissues in second group which received $7.5 \mathrm{mg} / \mathrm{kg} /$ day of MSG to severe changes in the third group that received $15 \mathrm{mg} / \mathrm{kg} /$ day of $\mathrm{MSG}$. This was consistent with Ortiz et al., (2006) who indicated that prolonged administration of MSG leads to different degrees of architectural destruction of the kidney and reduction in the number of renal corpuscle.

The present study indicated to marked reduction in PAS reaction in renal tissues of rats of third group which received $15 \mathrm{mg} / \mathrm{kg} /$ day of $\mathrm{MSG}$ and these results were in agreement with the results of Eweka et al., 
(2011) who reported that marked reduction of PAS reaction due to areas of hydropic degeneration and necrosis in renal tissues.

The current study reported that severe ultrastructural changes in renal tissues of third group which received $15 \mathrm{mg} / \mathrm{kg} /$ day of MSG such as swelling of the capillary endothelium of the glomeruli with narrowing of the capillary lumen, swollen mitochondria of proximal convoluted tubules cells and damage of brush-border microvilli. There were a mild degree of ultrastructural changes of renal tissues in the second group which received $7.5 \mathrm{mg} / \mathrm{kg} /$ day of MSG. These results were explained by Vinodini et al., (2010) who confirmed that mechanism of toxicity of MSG depends on oxidation damage and generation of reactive oxygen species (ROS) which causes lipid peroxidation, enzyme inactivation and oxidative damage of DNA regarding to dose and duration of administration of MSG.

Kuldip and Ahluwalia (2005) showed that toxic effect of MSG on the kidney due to the increase of malondialdhyde (MDA) which is an end product of lipid peroxidation because tissue glutathione and scavenging enzymes such as superoxidase dismutase (SOD) and catalase are decreased, so renal cellular injury occurs and then renal dysfunction will be resulted .

Onakewhor et al., (1998) reported that the alternative use of MSG as laundry bleach may be indicator to its toxic effects on different organs such as liver and kidney when it is taken by high dose because of its bleaching properties.

Oforofuo et al., (1997) indicated that rate of progression of renal cellular necrosis depends on the severity of toxicity of MSG which is determined by dose and duration of exposure.

\section{Conclusion}

Repeated use of monosodium glutamate leads to histopathological, histochemical ultrastructural changes and physiological dysfunction in the kidney depending on the dose of administration.

\section{Recommendations}

Intake of MSG should be restricted as much as possible. It is recommended that further researches in human should be performed to verify our results. We suggest further studies with other parameters of renal assessment to complete this work.

\section{References}

Alexander RH and Griffith JM (1992): Clinical/Nutritional Biochemistry. Basic Biochemical Methods. $2^{\text {nd }}$ ed., Wiley-Liss, New York. John Wiley and Sons.

Andrew OE (2007): Histological studies of the effects of MSG on the kidney of adult Wistar rats. The internet Journal of Health, Vol. 6 (2), 276-283.
Bancroft JD and Gamble M (2002): Theory and Practice Histological Techniques, 5th ed., Churchill Livingstone. New York, Edinburgh and London, pp 126 and 173-175.

Drury RA and Wallington EA (1980): Carlton Histological Technique $4^{\text {th }}$ Ed.Oxford Press, 6575.

Egbuonu ACC, Ejikeme PM, and Obasi LN (2010): Influence of sub-chronic oral exposure to high monosodium glutamate on some serum markers of the renal functions in male Wistar rats. African Journal of Biochemistry Research Vol. 4(9), pp. 225-228.

Egbuonu ACC, Obidoa O, Ezeokonkwo CA et al., (2009). Low dose oral administration of monosodium glutamate in male albino rats may be nephroprotective. Bio-Res., 7(1): 470-473.

Eweka AO, Igbigbi PS and Ucheya RE (2011): Histochemical Studies of the Effects of Monosodium Glutamate on the liver and kidney of Adult Wistar Rats. Ann Med Health Sci. Res. Jan., 1(1) 21-30.

Freeman M (2006): "Reconsidering the effects of monosodium glutamate: a literature review". J Am. Acad. Nurse Pract. 18 (10): 482-6.

Geha R, Beiser A, Ren C et al., (1998): Multicenter multiphase double blind placebo controlled study to evaluate alleged reactions to monosodium glutamate (MSG). J. Allergy Clin. Immunol. 101:S243

Kaplan LA, Szabo L and Ophenin EK (1988): Clinical Chemistry: Interpretation and Techniques 3rd ed., Philadelphia. Lea and Febiger.

Kuldip S and Ahluwalia P (2005): Alteration in some antioxidants enzymes in cardiac tissue upon monosodium glutamate administration to adult male mice. Indian Journal of Clinical Biochemistry, 20(1): 43-46.

Mozes S and Sefcikova Z (2004): Obesity and changes of alkaline phosphatase activity in the small intestine of 40 and 80-day old rats subjected to early postnatal overfeeding of monosodium glutamate. Physiol. Res., 53(2).

Oforofuo IAO, Onakewhor JUE and Idaewor PE (1997): The effect of Chronic Admin of MSG on the histology of the Adult Wistar rat Testes: Bioscience Research Communications. Vol. 9, No. 2, June: 30-56.

Onakewhor JUE, Oforofuo IAO, and Singh SP (1998): Chronic administration of monosodium glutamate induces Oligozoospermia and glycogen accumulation in Wister rat testes. Afr. J. Reprod. Health, 2(2): 190-197.

Ortiz GG, Bitzer-Quintero OK, Beas Zárate $\mathrm{C}$ et al., (2006): Monosodium glutamate-induced damage in liver and kidney: a morphological and biochemical approach Biomedicine and Pharmacotherapy (60) PP ( 86-91). 
Rogers PP and Blundell JE (1990): Umani and appetite: Effects of monosodium glutamate on hunger and food intake in human subjects. Phsiol. Behav., 486: 801-804.

Samuels A (1999): The Toxicity/Safety of MSG; A study in suppression of information. Accountability in Research, 6 (4): 259-310.

Stevenson D D (2000): Monosodium glutamate and asthma. J. Nutr. 130: 1067S-1073S.

Tawfik M S and Al-Badr N (2012): Adverse Effects of Monosodium Glutamate on Liver and Kidney Functions in Adult Rats and Potential Protective Effect of Vitamins C and E. Food and Nutrition Sciences, 3, 651-659.

Vinodini NA, Nayanatara AK, Ramaswamy $\mathrm{C}$ et al., (2010): Study on evaluation of monosodium glutamate induced oxidative damge on renal tissue on adult Wistar rats. J. Chin. Clin. Med., 5(3): 144-147.

Wilding P and Kennedy JH (1977): Manual of routine methods in clinical chemistry for use intermediate laboratories WHO Lab./78.1 p. 2528.

Willams A N and Woessner K M (2009) :"Monosodium glutamate 'allergy': menace or myth?". Clinical and Experimental Allergy 39: 640-646.

Zhang Z, Dmitrieva NI, Park JH et al., (2004): High urea and $\mathrm{NaCl}$ carbonylate proteins in renal cells in culture and in vivo, and high urea causes 8oxoguanine lesions in their DNA. Proc. Natl. Acad. Sci. U S A. 101(25): 9491-9496.

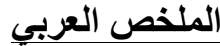 \\ تقييم السمية الكلوية للاستخدام المتكرر لجلوتاميد أحادي الصوديوم في الجرذان البيضاء البالغة \\ حسام الدين حسين عثمان1 و سعيد سعيد الثماع² أيمن المغاوري القتاوى 3}

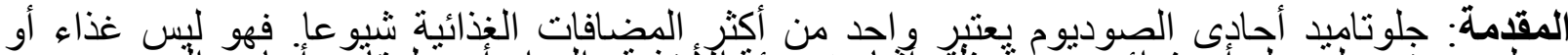

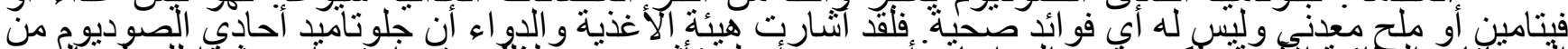

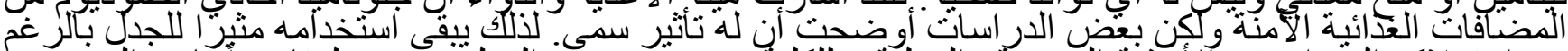

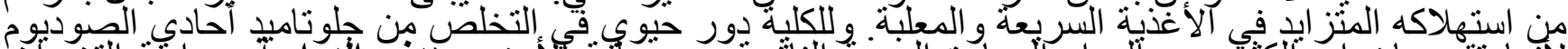

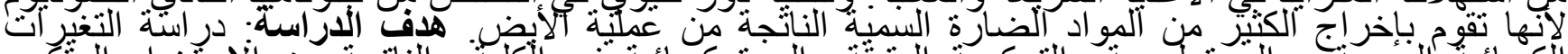

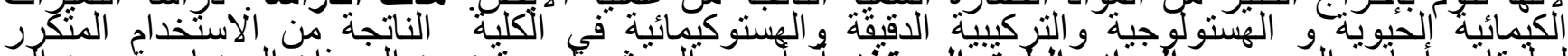

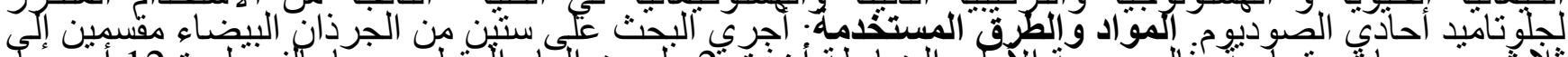

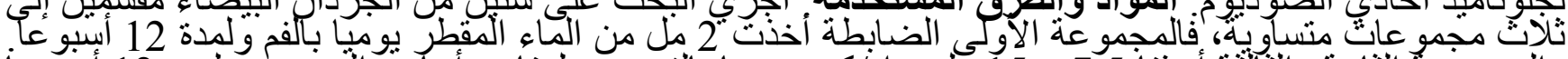

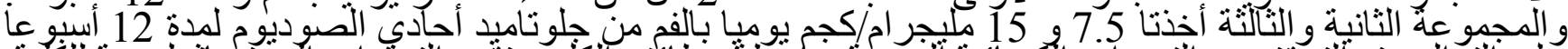

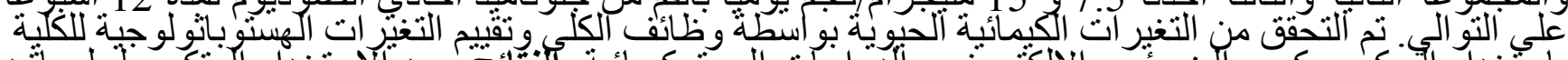

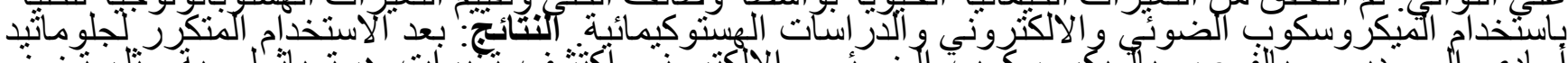

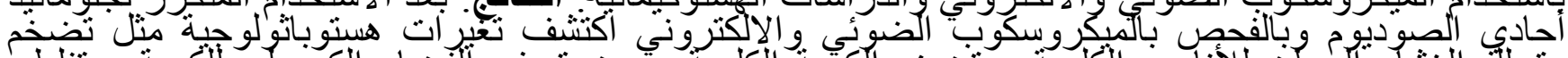

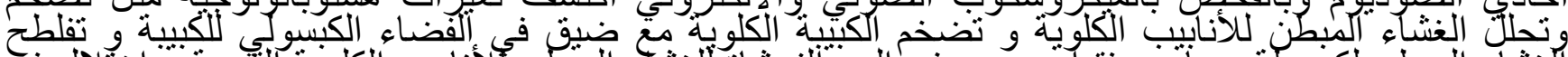

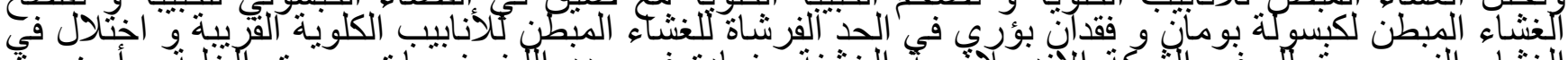

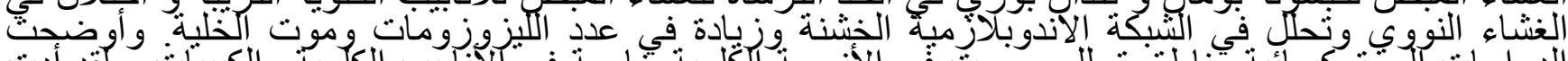

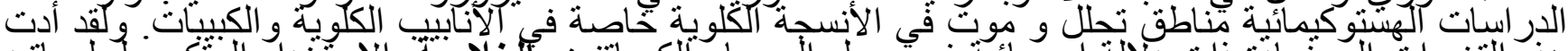

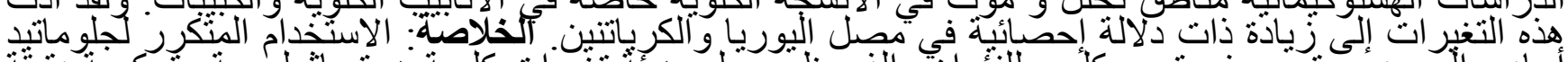

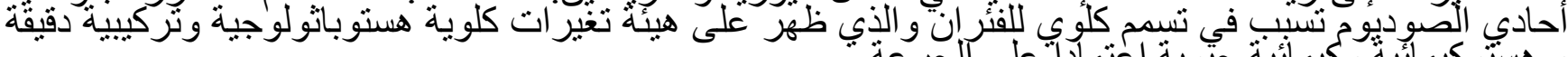

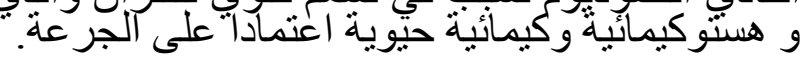

\footnotetext{
1 قسم التشريح كلية الطب جامعة الطائف و جامعة الأز هر

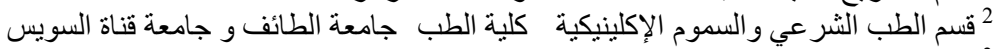

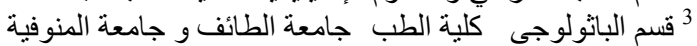

